\title{
CONSTRUÇÃO E CONSOLIDAÇÃO DE INSTITUIÇÕES DEMOCRÁTICAS papel do orçamento participativo
}

\author{
Celina Souza \\ Professora da Universidade Federal da Bahia, Pesquisadora visitante da USP
}

\begin{abstract}
Resumo: Na maioria das democracias recentes, governos e segmentos da sociedade vêm buscando mecanismos para fortalecer as instituições democráticas. Com esse objetivo, várias experiências têm sido desenvolvidas para aumentar a participação dos cidadãos no processo decisório de políticas públicas, em especial as de abrangência local. Uma dessas experiências é a do orçamento participativo. Este artigo analisa a literatura sobre o tema, particularmente a relativa às experiências de Porto Alegre e de Belo Horizonte. Palavras-chave: democracia; governo local; orçamento participativo.
\end{abstract}

$\mathrm{O}$ S movimentos de redemocratização que ocorreram na América Latina e no Leste Europeu nos anos 80 tomaram caminhos diferenciados, gerando resultados e experiências diversos. Apesar de esses países partilharem agendas comuns, existem experiências e problemas que os distinguem em termos de prática democrática. Sua agenda comum no que se refere à democracia dá prioridade à construção ou reconstrução de instituições democráticas. Essa agenda busca principalmente enfrentar a corrupção, aumentar a participação da sociedade no processo decisório sobre políticas públicas que as afetam diretamente e promover a transparência e a responsabilidade dos governos e dos gestores públicos. Em muitos países, essa agenda esteve associada à descentralização política e financeira para os governos subnacionais, o que significa que a tarefa de construção de instituições democráticas não se restringe às instituições nacionais.

O Brasil é um exemplo em que a redemocratização e a descentralização caminharam juntas. No que se refere à descentralização, já existe vasta literatura avaliando seus resultados, sobretudo na esfera local. Alguns desses trabalhos fazem uma leitura otimista da descentralização, vendo-a como capaz de "reinventar o governo" e aproximá-lo da comunidade pela conciliação de demandas coletivas e individuais, além de aumentar a governança ("bom governo") local. Outros mostram certo ceticismo quanto às possibilidades virtuosas da descentralização em um país mar- cado por alto grau de desigualdade social, econômica e regional (Arretche, 2000; Souza, 1997, por exemplo). Há trabalhos que chamam a atenção para os riscos de os governos locais promoverem políticas de exclusão social na competição por investimentos (Melo, 1996). Outra abordagem mostra que, em certas circunstâncias, a centralização pode ser essencial para a implementação de programas governamentais; os sociais principalmente (Tendler, 1997).

No que se refere à participação da comunidade, muitos governos locais no Brasil estão envolvidos no desenvolvimento desses mecanismos, que vão desde a criação de conselhos comunitários até o chamado orçamento participativo (OP). O OP tem sido visto, tanto na literatura nacional quanto na estrangeira, como um exemplo de instrumento de promoção do "bom governo" ou da boa governança urbana.

$\mathrm{O}$ entusiasmo e os relatos de sucesso sobre o OP trazem alguns paradoxos. Por que certos governos locais adotaram a política de ceder poder decisório aos mais pobres, em um país rotulado como clientelista e/ou elitista e que registra déficits históricos de engajamento cívico? Por que os governos locais optaram por adotar políticas que buscam a participação no processo decisório, quando os mesmos têm uma agenda congestionada de problemas locais não resolvidos em áreas como habitação, educação, saúde, transporte, etc.? Por que, em um tempo em que o individualismo é visto como sinônimo de liberdade, foram adotadas políticas que estimulam a cooperação e o acesso 
a bens coletivos para grupos historicamente excluídos do processo decisório? Por que, em um tempo marcado pelo desencantamento com os sistemas políticos e com os políticos, a comunidade responde positivamente ao chamado dos dirigentes para participar? Por que, em um tempo onde a opção da "saída" (exit) é mais valorizada que a da "voz" (voice) - na feliz síntese de Hirschman (1970) - as experiências participativas têm crescido? Por último, em um tempo em que a literatura dominante nas ciências sociais argumenta que os indivíduos (políticos, burocratas e eleitores) são movidos pelo auto-interesse, por que atores coletivos e individuais encontram incentivos à cooperação?

Este artigo analisa parte da literatura produzida sobre o OP, principalmente aquela sobre as experiências de Porto Alegre e de Belo Horizonte, debatendo as principais teses e argumentos encontrados nessa literatura sobre seu papel e objetivos. $\mathrm{O}$ artigo argumenta que, embora algumas teses e resultados sobre o OP de Porto Alegre e o de Belo Horizonte requeiram pesquisas mais aprofundadas, a experiência tem permitido que os segmentos de menor renda, que moram em áreas periféricas das cidades, possam decidir sobre as prioridades de investimentos em suas comunidades. Apesar de os recursos destinados ao OP ainda serem reduzidos, vis-à-vis outros itens do orçamento, a experiência tem mostrado que em um país como o Brasil, onde o acesso ao processo decisório é altamente desigual, o OP é uma das poucas alternativas capazes de transformar os investimentos públicos de favores em direitos e diminuir o desequilíbrio do poder decisório. Por outro lado, existem ainda lacunas na literatura que analisa o OP, em especial investigações mais aprofundadas sobre os tradeoffs de políticas que visam, no longo-prazo, a formas de autogoverno, bem como melhor conhecimento sobre as razões que explicam o sucesso do OP em algumas cidades brasileiras. Isso porque mudanças nas relações de poder requerem complexa engenharia política e a combinação de condições políticas, sociais e econômicas que ainda não estão, a meu ver, suficientemente claras. ${ }^{1}$

$\mathrm{O}$ artigo primeiro descreve algumas experiências de participação comunitária anteriores aos OPs de Porto Alegre e de Belo Horizonte, assim como alguns fatores e políticas que facilitaram a introdução do OP. A seção seguinte faz uma revisão da literatura que analisa as duas experiências, apontando os pontos de consenso e de discenso no que se refere a objetivos e resultados. A última seção avalia o OP, tentando chegar a algumas conclusões sobre seus principais resultados, debatendo as teses e os argumentos encontrados na literatura analisada.

\section{ANTECEDENTES DO ORÇAMENTO PARTICIPATIVO}

Alguns fatores e políticas antecederam e facilitaram a adoção de políticas como o OP. O primeiro é a existência de algumas experiências semelhantes, anteriores à redemocratização. O segundo é o aumento dos recursos municipais como resultado da redemocratização, combinado com a decisão de vários governos locais de promover ajustes nas respectivas finanças públicas. O terceiro fator é o aumento da presença de partidos considerados de esquerda nos governos locais, em especial nas grandes cidades.

\section{Experiências Participativas Durante o Regime Militar}

Ainda durante o regime militar, um pequeno número de municípios governado pelo então MDB adotou políticas participativas. Uma dessas experiências, analisada por Castro (1988), ocorreu em Piracicaba (SP), no período 1977-1982. ${ }^{2}$ Castro sugere que a motivação do prefeito em propor a participação direta da comunidade no processo decisório destinava-se a: a) mostrar aos governos federal e estadual que os recursos destinados a Piracicaba e vinculados a determinados projetos não atendiam às prioridades da comunidade; b) pressionar a Câmara de Vereadores para aprovar leis controvertidas. A avaliação de Castro foi a de que o processo participativo em Piracicaba teve caráter mais consultivo que deliberativo, apesar da criação de inúmeros conselhos, inclusive para o orçamento. Como em várias outras experiências similares, com a eleição do novo prefeito essa política desapareceu.

No mesmo período, em Lages (SC), outra experiência ganhou visibilidade nacional. Como em Piracicaba, o prefeito de Lages, Dirceu Carneiro, também pertencia ao MDB, mas a principal marca dessa gestão não foi estimular a participação no processo orçamentário e sim na promoção de pequenas iniciativas de intervenção urbana, implementadas cooperativamente entre o governo e a comunidade. Mudou-se também o foco do planejamento urbano, que deixava de ser abrangente para concentrar-se nos problemas do cotidiano da população (Ferreira, 1991). Apesar de o objetivo ter sido governar com a participação popular, não havia organização da comunidade e o governo local interveio para promover a mobilização e estimular a criação de associações comunitárias. Por causa da falta de organização da comunidade, a experiência de Lages, embora vista como paradigmática, não pode ser 
considerada como tendo atingido seu objetivo. Isso porque, ainda de acordo com Ferreira (1991), a participação teve de ser construída lentamente e seus instrumentos não foram suficientes para influenciar decisivamente as prioridades definidas pelo governo local. O programa mais bem-sucedido acabou sendo o sistema de mutirão para a construção de moradias para a população pobre. Os mutirões foram popularizados e posteriormente adotados em várias cidades brasileiras, independentemente de orientações partidárias ou ideológicas. Na avaliação de Ferreira (1991), superestimou-se o poder da aliança com os pobres e subestimou-se o poder de seus opositores. Ademais, a administração não foi capaz de mudar as relações de poder na cidade. Seu mérito esteve na criação de formas alternativas para lidar com os problemas de sobrevivência dos mais pobres, por meio de iniciativas rápidas e baratas, sustentadas na organização popular.

Mecanismos de participação popular em três cidades de Minas Gerais, administradas pelo MDB entre 1983 e 1988, foram analisados por Costa (1997). O autor mostrou ceticismo em relação a essas experiências, argumentando que elas tendiam a transformar líderes populares e suas associações em intermediários de interesses políticos que se distanciavam das necessidades do povo. O autor conclui que a cultura política que emerge após regimes autoritários e uma sociedade civil ativa são difíceis de conciliar e que a esfera administrativa não é a melhor situação para a construção de formas de vida democrática.

Além dos casos acima descritos, outras avaliações desse período foram feitas por instituições como o Instituto Pólis. ${ }^{3}$ Um desses trabalhos analisa a experiência de Fortaleza, primeiro governo local eleito pelo PT, em 1986. A experiência foi considerada um fracasso em termos de participação popular em virtude do isolamento do governo e de suas controvérsias com o partido. Um dos pontos positivos, no entanto, foi ter deixado marcada para a população a separação entre a prefeitura e o governo estadual (Pinto, 1992). Isso porque Fortaleza, assim como várias cidades brasileiras naquele momento, em especial no Nordeste, eram administradas como um segmento do governo do estado por causa da enorme escassez de recursos e da influência do governador do estado na nomeação dos prefeitos das capitais.

\section{Aumento das Receitas Municipais}

O segundo fator que contribuiu para a expansão das políticas participativas foi o aumento das receitas municipais logo após a abertura política e, posteriormente, com a Constituição de 1988. Mas não só o aumento das receitas municipais trazidas pela redemocratização tiveram impacto positivo sobre essas políticas. Tão ou mais importante foi a decisão de alguns governos locais de proceder ao ajuste fiscal. Esse dado é em geral pouco mencionado na literatura, mas é de crucial importância porque a reforma tributária promovida pela Constituição de 1988 foi uma reforma em fases, só tendo se completado em 1993, após, portanto, a institucionalização do OP em Porto Alegre.

Ademais, não apenas cidades como Porto Alegre ou outras governadas por partidos mais à esquerda, mas vários municípios brasileiros adotaram a política de ajuste fiscal, aumentando também os recursos próprios. Jayme Jr. e Marquetti (1998) mostram que apesar do esforço de Porto Alegre no sentido de aumentar sua arrecadação ter sido grande - entre 1989 e 1994 a cidade passou da $10^{\mathrm{a}}$ para a $5^{\text {a }}$ posição no ranking da arrecadação per capita entre as capitais -, ela não foi a única grande cidade a experimentar esse crescimento. A maior mudança relativa se deu em Belo Horizonte, que passou da $22^{\mathrm{a}}$ para a $4^{\mathrm{a}}$ posição, no mesmo período. Os autores citados mostram também que, no que se refere à receita própria, Belo Horizonte registrou maior incremento do que Porto Alegre $23,99 \%$ e $11,3 \%$, respectivamente. A literatura que analisa os OPs de Porto Alegre e de Belo Horizonte raramente destaca esse ponto ou, em geral, menciona apenas os incrementos de Porto Alegre. ${ }^{4}$

Um aspecto no caso de Belo Horizonte merece destaque: os aumentos registrados mostram o quanto os contribuintes locais estavam sendo subtaxados. Revelam também que muitos prefeitos eleitos, diferentemente dos nomeados, optaram pelo aumento de receitas próprias para tentar cumprir seus compromissos com os eleitores, em lugar de apoiar-se exclusivamente no aumento das transferências federais e estaduais estabelecido pela Constituição de 1988. Essa política contradiz a hipótese da literatura sobre federalismo fiscal, a qual pressupõe que os governos subnacionais, ao ampliar sua participação nas transferências intergovernamentais, tendem a fazer poucos esforços no sentido de aumentar as receitas próprias. Por outro lado, deve ser registrado também que Porto Alegre e Belo Horizonte são cidades com melhores indicadores econômicos e sociais que a média das cidades brasileiras. Isso dá a seus governantes mais oportunidades para aumentar as receitas próprias, garantindo-lhes mais recursos livres para implementar programas redistributivos como o OP. 


\section{Crescimento dos Governos Locais Governados pela Esquerda}

O terceiro fator que contribuiu para a difusão de programas participativos está associado ao crescimento dos partidos de esquerda nos governos locais, especialmente o PT. Em 1988, 32 prefeitos pertenciam ao PT; em 1992, 53; em 1996, 115 e em 2000, 187. Como uma das bandeiras do PT é a participação, passou a haver incremento de experiências como o OP. Essas experiências são constantemente analisadas e disseminadas por militantes partidários, acadêmicos, órgãos de pesquisa e ONGs. A conquista de maior fatia nos governos locais tem dado ao PT a oportunidade de debater e de pôr em prática seus compromissos eleitorais, onde o OP é um dos de maior visibilidade. Além do mais, o sucesso inicial e a divulgação de grande número de experiências participativas como o OP têm funcionado como marca positiva para o partido.

Essa seção mostrou que as origens de políticas participativas remonta a experiências anteriores aos OPs de Porto Alegre e de Belo Horizonte e que essas experiências não se restringem aos governos administrados pelo PT. Na verdade, o OP de Belo Horizonte surgiu muito depois do de Recife e Fortaleza. Seja porque estas cidades não eram administradas pelo PT quando essas experiências ocorreram ou porque seus resultados são de fato mais modestos que os de Porto Alegre e de Belo Horizonte, elas são menos conhecidas e estudadas. ${ }^{5}$ Os OPs de Porto Alegre e de Belo Horizonte, analisados a seguir, certamente extraíram lições das experiências anteriormente mencionadas. Existem, no entanto, importantes diferenças entre essas experiências para além da questão temporal e da mudança de regime político. A primeira é que o OP, em Porto Alegre e em Belo Horizonte, vem sobrevivendo a diferentes mandatos de governo. A segunda é que essas cidades concentraram os esforços da experiência participativa no processo orçamentário, isto é, na decisão sobre como alocar recursos escassos, trazendo para o centro do debate questões sensíveis como desigualdade, pobreza, desequilíbrio de poder nas cidades brasileiras e rearranjos na intermediação de interesses locais.

\section{ORÇAMENTO PARTICIPATIVO EM PORTO ALEGRE E EM BELO HORIZONTE}

A participação dos cidadãos nas políticas públicas não é nenhuma panacéia nem muito menos uma tarefa fácil, como mostram as experiências de Porto Alegre e de Belo
Horizonte. ${ }^{6}$ Além do mais, o conceito de participação não é claro nem consensual, mesmo dentro do partido mais associado ao conceito - o PT. Problemas ainda mais complexos surgem quando a participação resulta, como no caso do OP, de um programa liderado e induzido pelo governo, ou seja, é uma política que vem "de cima".

Nylen (2000a:132) argumenta que, depois de muito debate, parece emergir um consenso nos governos locais de esquerda sobre os principais objetivos de uma administração "democrática e popular": inverter prioridades e promover a participação do povo. O primeiro objetivo refere-se à formulação de uma política capaz de favorecer os pobres pela taxação daqueles que tenham capacidade de pagar. O segundo objetivo remete ao conceito de empowerment ("empoderamento"), ou seja, a uma forma de consciência política que faz a crítica das desigualdades e injustiças existentes mas, ao mesmo tempo, é capaz de ver na ação coletiva a forma de alcançar reformas progressivas (Nylen, 2000a). À avaliação de Nylen (2000a) pode-se acrescentar a da busca do autogoverno local para determinados segmentos sociais e para algumas políticas públicas. ${ }^{7}$

As experiências de OP em Porto Alegre e em Belo Horizonte tiveram início com a vitória do PT na eleição para prefeito. Em Porto Alegre, ela se iniciou em 1989, um ano após a posse; em Belo Horizonte, em 1993, no mesmo ano da posse. Ambas as experiências ainda continuam sendo as principais marcas das gestões municipais nessas cidades e já foram objeto de várias sínteses e análises. Dentre os que analisaram a experiência de Porto Alegre, estão Abers (1998, 2000), Dias (2000) Jacobi e Teixeira (1996), Fedozzi (1997), Laranjeira (1996), Matthaeus (1995), Navarro (1997), Santos (1998) e Wampler (2000). O OP de Belo Horizonte foi analisado, entre outros, por Azevedo (1997), Azevedo e Avritzer (1994), Boschi (1999a), Nylen (2000a; 2000b), Pereira (1996; 1999) e Somarriba e Dulci (1997). Essa extensa produção traz informações e análises sobre o funcionamento do OP, principalmente quanto a prioridades de investimentos; recursos financeiros; forma de escolha dos delegados e seu perfil socioeconômico; organização administrativa das prefeituras e as mudanças nela promovidas por força do OP; papel da burocracia; papel dos delegados do OP ante o dos vereadores; relação da Câmara de Vereadores com as prefeituras; pesquisas de opinião sobre o OP; efeitos do OP sobre questões como transparência e accountability dos governos locais e dos gestores públicos; outras formas de participação envolvendo seto- 
res da comunidade que não participam do OP. Ademais, ambas as prefeituras mantêm nos seus sites informações detalhadas sobre o OP.

Essa abrangente e extensa produção dispensa que sejam aqui exibidos dados, procedimentos e o funcionamento do OP. Pode-se, então, avançar diretamente para os objetivos deste artigo: debater as principais teses e argumentos relacionados com o OP e seu papel na construção de instituições democráticas, da cidadania e do auto-governo local.

\section{COMO A LITERATURA INTERPRETA O ORÇAMENTO PARTICIPATIVO?}

No final dos anos 80, muitos governos locais introduziram mecanismos de incentivo à participação das comunidades no processo decisório das políticas públicas locais. Parece haver um consenso de que políticas participativas são um objetivo virtuoso para os países do chamado Terceiro Mundo, especialmente os recém-democratizados. Esse consenso é tão forte que reúne os extremos do espectro político: dos conservadores à esquerda; das organizações multilaterais de financiamento mais comprometidas com a distribuição de renda até as que premiam as best practices. Assim, participação transformou-se na palavra mágica de todo projeto de governo local e no "abre-te sésamo" dos financiamentos internacionais.

Como já foi mencionado, existe vasta literatura que analisa experiências participativas nas políticas públicas locais. Essa literatura transcende os cortes das disciplinas e áreas acadêmicas porque relaciona temas como descentralização, democracia, capital social, accountability, desenvolvimento, governança ("bom governo"), "empoderamento" de grupos sociais excluídos, educação cívica, justiça social, desenvolvimento sustentável e gestão urbana. No Brasil, essa literatura tem sido produzida por centros acadêmicos, ONGs, organizações multilaterais e vários organismos nacionais que financiam pesquisas. ${ }^{8}$

Existe um consenso na literatura analisada de que, apesar dos problemas, tensões e resultados não previstos que decorrem do OP, a experiência tem-se constituído em forma de acesso do cidadão ao processo decisório local. Esse acesso, no entanto, é induzido e coordenado pelos governos. Quais as bases para a avaliação desse sucesso? A visão de sucesso contraria, em parte, a literatura teórica e empírica sobre participação, em geral cética quanto ao papel do Estado na construção de instituições democráticas e possibilidades da participação popular. Segun- do mapeamento de Abers (2000), a literatura aponta três "problemas" da participação. O primeiro é o "problema de implementação", isto é, mesmo quando os governos buscam implementar mecanismos participativos voltados para integrar grupos menos poderosos no processo decisório, os mais poderosos têm força para impedir essa participação. O segundo é o "problema da desigualdade": mesmo quando espaços são criados para que todos participem, as desigualdades socioeconômicas tendem a criar obstáculos à participação de certos grupos sociais. O terceiro é o "problema da cooptação": mesmo que os espaços de participação sejam genuinamente representativos, o desequilíbrio entre o governo e os participantes, no que se refere ao controle da informação e dos recursos, faz com que a participação seja manipulada pelos membros do governo.

Apesar dessas visões, a literatura que analisa o OP de Porto Alegre e de Belo Horizonte avalia-os como bemsucedidos, ao menos no que se refere a seus objetivos. No entanto, as razões desse sucesso variam tanto quanto o rótulo que cada autor dá ao OP. Isso porque a participação significa coisas diferentes para pessoas ou grupos diferentes. Para alguns autores, a participação é uma forma de aumentar a eficiência dos governos; para outros, ela implica o aumento da justiça social, ou seja, o acesso de pessoas e grupos historicamente excluídos do processo decisório. Outros advogam que a participação é mera retórica de políticos e governantes. Conforme a síntese de Abers (2000), para alguns, os benefícios da participação limitam-se a fatores instrumentais, isto é, aumento da efetividade da política pública, promoção de consenso sobre as ações governamentais e acesso a informações detalhadas sobre as necessidades reais dos cidadãos comuns. Para os que elegeram o OP como política prioritária, no entanto, o principal objetivo da participação é a delegação de poder aos grupos sociais que foram ignorados pelas políticas anteriores de desenvolvimento local. O significado da participação, portanto, é o primeiro grande divisor de águas tanto na literatura analisada como no próprio conceito de participação.

\section{Participação Como Voz ou Como "Empoderamento"?}

Para a maioria dos organismos multilaterais, participação significa voz no processo decisório e não autonomia para tomar decisões. Para esses organismos, "a voz dos cidadãos locais, particularmente a dos pobres, pode 
ser aumentada por reformas na esfera nacional que permitam a esses segmentos maior liberdade para aderir a organizações não-governamentais, sindicatos ou outras instituições, a fim de melhor entender e influenciar decisões que os afetam" (World Bank, 1994:42 - tradução da autora). Assim, para grande parte das organizações multilaterais, a participação é uma forma de transformar os desorganizados em membros de uma sociedade civil que podem influenciar (mas não decidir) questões que os afetem diretamente. Essa visão dá ênfase a resultados de curto prazo e propostas de enfrentamento de problemas específicos, em lugar de transformações de longo prazo e de natureza estrutural. Por outro lado, essa visão demonstra cautela em relação aos limites da participação popular no contexto da democracia representativa.

A visão instrumental e cautelosa da participação não é a que orienta o OP de Porto Alegre e de Belo Horizonte. Como já foi dito, para o PT, a participação significa dar poder aos pobres para que eles: a) tomem consciência das iniquidades e injustiças (crescimento da consciência política); e b) reformem os sistemas político e social pela via da ação coletiva.

Como resultado dessas visões "rivais" sobre o papel da participação, surge uma questão: é possível adotar o $\mathrm{OP}$ em todas as cidades brasileiras? Mesmo na visão menos ambiciosa dos organismos multilaterais, a resposta não é fácil. Existem constrangimentos empíricos e teóricos que podem dificultar a adoção indiscriminada do OP. Esses constrangimentos podem ser assim sintetizados:

- por que representantes eleitos iriam querer dividir o poder, mesmo que de forma apenas consultiva?

- por que indivíduos racionais iriam querer participar, dado o desencantamento com a política e os políticos que as pesquisas de opinião vêm sistematicamente mostrando em todo o Brasil?

- como esses programas podem evitar a questão do "carona" (free-riding)?

- os municípios brasileiros no seu conjunto têm recursos suficientes para cumprir o que for decidido pela população?

- como evitar manipulação, corrupção e clientelismo em cidades onde a população tem baixa escolaridade, não está acostumada a ter papel ativo na fiscalização dos governos e onde a maioria é tão pobre que todo seu esforço e tempo tem que ser canalizado para a própria sobrevivência?

- como governos que buscam a participação podem convencer as pessoas a se dedicar a problemas coletivos em vez de lutar por suas necessidades imediatas, inclusive porque muitos desses programas são abolidos quando um novo grupo político assume o governo? ${ }^{10}$

- como conciliar a prática de políticas participativas voltadas para o autogoverno com as instituições formais da democracia representativa, em especial com o legislativo local?

O grande número de conselhos comunitários hoje existentes no Brasil não parece responder a essas questões. Estimulados por programas nacionais ou por financiamentos internacionais que condicionam a liberação de recursos à criação desses conselhos, todos os municípios brasileiros tiveram que instituir inúmeros conselhos comunitários para o desempenho de suas funções básicas. Muitos deles parecem apenas reproduzir o que as regras exigem, eliminando, portanto, as premissas básicas da participação: credibilidade, confiança, transparência, accountability, "empoderamento", etc. Apesar de incipientes as pesquisas sobre esses conselhos, existem acusações de controle dos prefeitos sobre seus membros, aliado a suspeitas de corrupção no uso dos recursos, em especial nos municípios mais pobres e nos setores de educação e saúde, os que demandam recursos mais vultosos.

Se a proposta mais modesta da participação encontra os obstáculos mencionados, o que dizer da possibilidade de se ampliar o OP nos termos da proposta do PT, ou seja, a de "empoderamento" dos pobres, dando-lhes autoridade para decidir e não apenas serem ouvidos? Alguns autores analisados enfrentaram essa questão. Uns argumentam que o OP só é possível em Porto Alegre (Abers, 2000) pela combinação de três fatores. Primeiro, o OP se transformou em estratégia política para que o PT adquirisse capacidade de governar, transformando-se na marca registrada do governo local. O OP também foi usado para desmontar as velhas bases do populismo em Porto Alegre, lideradas pelo PDT. Segundo, o governo local foi capaz de mudar o custo-benefício da ação coletiva em relação aos pobres e menos organizados, ao diminuir os custos da adesão dos pobres ao OP por meio do papel dos organizadores da comunidade. Terceiro, o governo foi capaz de aumentar as expectativas em relação aos benefícios por dar prioridade à dotação de infra-estrutura para as comunidades pobres. Essa tese, todavia, não explica o caso de Belo Horizonte, embora algumas das razões para o sucesso do OP em Porto Alegre também possam ser encontradas na capital mineira.

A tese de que o OP produziu a delegação de poder aos grupos pobres e desorganizados é contestada pelos dados de Nylen (2000b) e pelo nível de renda dos participantes. 
Uma pesquisa conduzida por Nylen (2000b) mostrou que tanto antes do OP como no momento da pesquisa, os delegados do OP de Belo Horizonte já participavam anteriormente de associações de bairro $(52,2 \%$ antes do OP e $64,5 \%$ depois do OP) e de grupos religiosos ( $40 \%$ antes do $\mathrm{OP}$ e $40,1 \%$ depois do OP). O número daqueles que nunca haviam participado de movimentos organizados era de $19,7 \%$ antes do OP e $12,2 \%$ no momento da pesquisa. Dados semelhantes foram encontrados por Nylen (2000b) em Betim, outra cidade mineira que adotava o OP. No que se refere à renda, uma pesquisa de Abers (1998) em dois distritos de Porto Alegre que participavam do OP mostrou que $40 \%$ dos entrevistados tinha renda familiar mensal de cerca de $\mathrm{R} \$ 400,00$ e que $18 \%$ ganhavam entre $\mathrm{R} \$ 400,00$ e R\$ 700,00 por mês. Esses dados confirmam os de uma pesquisa mais abrangente, cobrindo todos os distritos. Pesquisa de Somarriba e Dulci (1997:401) para Belo Horizonte, traçando o perfil dos participantes do OP, não traz informação sobre renda, mas afirma, considerando o grau de instrução e a atividade profissional dos participantes, que os mesmos provêm de vários estratos sociais, com significativa presença de setores médios. Nas palavras dos autores, "isso parece indicar que o OP não se restringe aos grupos sociais mais pobres, sensibilizando também outras camadas da população do município".

A resposta de Matthaeus (1995) sobre as possibilidades de implantação do OP em outras cidades brasileiras é a de que ela só é viável se o partido que estiver no poder for de esquerda. Santos (1998) parece concordar com a tese de Abers, mas por razões diversas. Para ele, o OP funciona em Porto Alegre porque é uma cidade de ampla tradição democrática e com uma sociedade civil altamente organizada. Dados trabalhados por Setzler (2000) mostram que, de fato, Porto Alegre registra os mais altos índices de associativismo, consciência política e confiança comunitária dentre as capitais brasileiras. A experiência do OP em Belo Horizonte, no entanto, embora combinando, de acordo com os analistas, estratégias diferentes da de Porto Alegre, na medida em que tenta conciliar a participação com formas de clientelismo, tem também sido avaliada como bem-sucedida, apesar de Belo Horizonte registrar níveis mais baixos de associativismo do que Porto Alegre. ${ }^{11}$

Navarro (1997) também enfrenta a questão sobre se o OP pode ser reproduzido em outras cidades e sob diferentes condições. Embora o autor relacione várias precondições para o OP (vontade política para ceder poder às associações, postura política contra o clientelismo, controle financeiro e recursos a investir), ele conclui que o OP pode ser generalizado nas administrações locais.

O grande divisor de águas aqui discutido coloca ainda outra questão: será que a participação no sentido do "empoderamento" só é possível em experiências similares às do OP? Alguns argumentam que políticas de financiamento direto aos pobres, sem a intermediação do governo, são mais importantes para se alcançar uma "gestão urbana pelos cidadãos", enquanto que o OP é uma "gestão urbana com os cidadãos (Matthaeus, 1995). Essa alternativa é negada por Abers (1998). Seja qual for a visão, existe consenso na literatura analisada de que, no caso de Porto Alegre, o "empoderamento" (ao menos daqueles que participam diretamente do OP) foi possível graças às condições mapeadas por Abers (1998) e Santos (1998). Em Belo Horizonte, no entanto, Boschi (1999b) sinaliza que o sucesso do OP deve ser creditado às experiências prévias de descentralização.

\section{Orçamento Participativo como Forma de Inverter Prioridades}

Sobre se o OP tem de fato refletido as prioridades dos pobres, a maioria dos autores analisados acredita que sim (Santos, 1998; Somarriba e Dulci, 1997; Pereira, 1996; Abers, 1998; Nylen, 2000a). Os delegados que participaram das pesquisas em Porto Alegre e em Belo Horizonte concordam. Não é tão claro, no entanto, se o OP tem refletido as necessidades daqueles que não participam, em particular dos muito pobres. Essa é uma questão importante porque, apesar de o apoio ao OP em ambas as cidades ser alto, a maioria dos cidadãos pobres não participa do processo. Os resultados de pesquisa feita em $1991 \mathrm{em}$ 150 municípios do Brasil mostram que os eleitores mais pobres e com menor escolaridade dão prioridade a questões ligadas à sobrevivência (custo de vida, baixos salários e oportunidades de emprego) e não à infra-estrutura dos lugares onde vivem. Na medida em que a renda ultrapassa o salário mínimo, a preferência dos eleitores muda para a provisão de bens e serviços públicos (Desposato, 2000). Apesar de a pesquisa ter sido realizada há 10 anos, pode-se inferir que suas conclusões continuam válidas. Caso essa hipótese esteja correta, pode-se também concluir que o OP não atinge as demandas dos muito pobres, mas sim as de uma parte da população que, embora não totalmente pobre, acredita que o OP vem suprindo a negligência das administrações locais anteriores em relação às péssimas condições de infra-estrutura das áreas de baixa renda. 
Outras questões também surgem como resultado do que foi discutido até aqui. Existem evidências que apóiam a tese de que o OP: a) aumenta a capacidade dos grupos sociais excluídos de influenciar a alocação dos recursos públicos; e b) amplia o acesso dos pobres aos serviços urbanos básicos. A literatura analisada permite afirmar que o OP expande a capacidade desses grupos de influenciar decisões e que aumenta seu acesso a serviços urbanos básicos, principalmente de infra-estrutura. Como foi sintetizado por Navarro (1997:5), "mesmo que muitas mudanças não sejam visíveis - por exemplo, o sentido da 'democratização do poder local' ou as mudanças nas várias formas de relação entre o governo local e a população -, é inegável, no entanto, que outras mudanças e resultados concretos podem ser encontrados em muitos lugares de Porto Alegre. Esses resultados se refletem na operação dos serviços públicos, que melhorou substancialmente nos últimos nove anos, após o OP. Maior racionalidade administrativa e eficiência fazem parte desses resultados, mas também mais justiça social na alocação dos recursos públicos" (tradução da autora).

O reconhecimento de que, com o OP, grupos excluídos ganharam influência sobre as políticas públicas e melhor acesso aos serviços urbanos básicos pode ser também inferido pelas respostas do eleitorado às coalizões que introduziram o OP: os eleitores reelegeram as coligações partidárias que implantaram o OP quatro vezes em Porto Alegre e três vezes em Belo Horizonte. Associar esses resultados eleitorais ao $\mathrm{OP}$ não é irrealista, dado que o OP é a política mais conhecida dessas coalizões.

Essa comprovação implica que o OP é também um instrumento capaz de contribuir para aumentar a democracia? Abers (2000) acredita que sim para o caso de Porto Alegre e Somarriba e Dulci (1997) para o caso de Belo Horizonte. Navarro (1997) qualifica o OP em Porto Alegre como uma espécie de "democracia afirmativa", graças às conquistas em assegurar efeitos redistributivos em um país onde existe tradicionalmente assimetria de poder. Visão menos otimista sobre esse potencial do OP é dada por Nylen (2000a), mas as razões apontadas baseiamse em indicadores nacionais por demais abrangentes. Dias (2000) debate os dilemas introduzidos pelo OP na questão da democracia representativa. Hipótese mais realista talvez seja a de que o OP tem efeito no aumento da democracia local, dado que agrega representantes de segmentos de baixa renda que raramente têm a oportunidade de chegar à arena decisória governamental; ao mesmo tem- po, porém, obscurece o papel de importante instituição do sistema representativo formal - o legislativo local.

\section{O Que É, Afinal, o Orçamento Participativo?}

Outro grande divisor de argumentos e teses está na forma como a literatura interpreta o OP. As visões são tão diversas que tornam difícil uma síntese. Como tentativa de agregar todas as respostas - e mesmo visões diversas dadas pelo mesmo autor - elas foram divididas em quatro blocos: gestão, educação, política e mudança social.

No terreno da gestão, existe a visão de que o OP é: a) gestão urbana com os pobres (Matthaeus, 1995); b) mecanismo de gestão conjunta dos recursos públicos através de decisões compartilhadas sobre a alocação dos recursos orçamentários (Santos, 1998); c) modelo de gestão urbana mais do que uma política pública (Boschi, 1999a e b); e d) processo de gestão fiscal social (Navarro, 1997).

No terreno da educação, a maior parte da literatura considera o OP um processo educativo que envolve todos os atores locais importantes - prefeito, burocratas, vereadores, movimentos sociais e o PT - , assim como as instituições nas quais esses atores operam. Essa visão é tributária do pensamento de Stuart Mill sobre o papel educativo do governo local.

No terreno político, as visões são bastante diversas. O OP é: a) uma política pública em que os que têm poder o cedem para os grupos em desvantagem (Abers, 2000); b) uma forma de radicalizar a democracia e o resultado de uma grande vontade política, capaz de permitir a construção de uma cultura política, que aumente a conscientização sobre a cidadania, e de melhorar as condições de vida da população (Villas Boas, 1994); c) uma das formas correntes de globalização contra-hegemônica (Santos, 1998); d) uma forma de combinar democracia representativa com participação (Jacobi e Teixeira, 1996); e e) um instrumento para superar os limites da democracia representativa através de mecanismos que ampliem a mobilização da sociedade civil para além do corporativismo e da simples consulta (Laranjeira, 1996). Contrariando as visões correntes sobre o OP, Dias (2000) argumenta que a experiência tem sido uma forma de o Executivo municipal sobrepor-se ao Legislativo.

Ainda no território do papel político do OP, aparece na literatura a visão de que o programa aumenta a transparência, accountability e a credibilidade dos governos e seus participantes. O OP também é constantemente mencionado como forma de eliminar (ou diminuir) o cliente- 
lismo, o autoritarismo e o patrimonialismo. Assim, embora com opiniões altamente divergentes, a literatura chega quase sempre à mesma conclusão: o OP está mudando a vida política de Porto Alegre e de Belo Horizonte.

Por fim, no terreno da mudança social, os autores concluem que o OP permite: a) a distribuição mais justa de recursos escassos em uma sociedade altamente desigual (Santos, 1998); b) um instrumento inovador para a reconstrução da vida pública (Somarriba e Dulci, 1997); c) nova forma de relacionamento entre o poder público local, as organizações populares e o resto da sociedade, a fim de atender às demandas dos segmentos mais pobres da população (Pereira, 1996); d) o fortalecimento do associativismo urbano e do relacionamento entre as associações comunitárias e os moradores dos distritos (Pereira, 1999); e) uma forma justa de decidir sobre a alocação de recursos (Jacobi e Teixeira, 1996).

\section{A Questão da Representação Política}

A questão mais sensível relacionada com o OP talvez seja a ameaça de que a participação comunitária possa substituir o papel dos burocratas, do executivo local e dos vereadores. A questão é particularmente sensível entre os delegados do OP e os vereadores. Como se sabe, a aprovação final do orçamento é uma competência constitucional do Legislativo. A fronteira entre essas duas formas de representação de interesses está longe de ser definida com clareza.
No que se refere à burocracia, a maior parte da literatura atesta sua resistência inicial ao OP, mas afirma que existem formas de superá-la. Santos (1998), por exemplo, argumenta que os burocratas também estão sendo submetidos a um processo de aprendizagem quanto à comunicação e ao diálogo com os cidadãos, que são leigos em matéria orçamentária. Santos admite, todavia, que o caminho da tecnoburocracia para a "tecnodemocracia" é acidentado. Como lembra Navarro (1997), no entanto, o conhecimento técnico é uma exigência essencial do OP. Quanto à relação entre os participantes do OP e o executivo local, existe consenso de que o governo local desempenha papel decisivo no OP, mesmo quando os participantes o contestam.

Na expressão de Santos (1998), todavia, o "contrato político", entre o executivo e as comunidades ainda não se estendeu ao legislativo. Embora Somarriba e Dulci (1997) não vejam problemas nessa relação, eles parecem existir e a fórmula pragmática encontrada em Belo Horizonte para acomodar as demandas dos vereadores no sentido de continuar a apresentar emendas ao orçamento que favoreçam seus eleitores mostra que a adesão do legislativo ao OP está longe de ser assegurada. ${ }^{12}$ Quanto a Porto Alegre, Dias (2000) identifica o papel dos vereadores como oscilando entre o que denomina de "constrangimento" ante a participação popular, "renúncia" a parcela de seu poder decisório e "reação" contra o Executivo, com a prevalência da renúncia. Segundo a mesma fonte, no entanto, os vereadores de Porto Alegre focalizam suas críticas e es-

QUADRO 1

Síntese das Principais Vantagens e Problemas do OP, de Acordo com a Literatura Selecionada Porto Alegre e Belo Horizonte

\begin{tabular}{|c|c|}
\hline Vantagens & Problemas \\
\hline $\begin{array}{l}\text { - Torna a democracia representativa aberta à participação mais ativa de segmen- } \\
\text { tos da sociedade civil } \\
\text { - Reduz clientelismo, populismo, patrimonialismo e autoritarismo, mudando a } \\
\text { cultura política e aumentando a transparência } \\
\text { - Estimula o associativismo } \\
\text { - Facilita o processo de aprendizado sobre melhor e mais ativa cidadania } \\
\text { - Desloca prioridades dos segmentos privilegiados para beneficiar a maioria da } \\
\text { população (os pobres); paralelamente, tenta abrir canais de participação a ou- } \\
\text { tras classes sociais } \\
\text { - Permite equilibrar bandeiras ideológicas voltadas para a delegação de poder } \\
\text { aos cidadãos com respostas pragmáticas que atendam a suas demandas } \\
\text { - Estabelece uma organização que pode sobreviver a mudanças de governo } \\
\text { - Estimula os participantes a trocar visões individualistas por solidárias e a ver os } \\
\text { problemas da cidade de forma coletiva }\end{array}$ & $\begin{array}{l}\text { - A interação com o governo coloca em risco a independência dos movimentos } \\
\text { comunitários } \\
\text { - Formas de clientelismo ainda sobrevivem } \\
\text { - A sociedade civil ainda está em formação } \\
\text { - Limitações financeiras e de recursos para o OP, reduzindo a abrangência dos } \\
\text { programas. As comunidades tendem a parar de participar quando suas deman- } \\
\text { das são atendidas } \\
\text { - Persistem dificuldades para aumentar a participação: os jovens, as classes } \\
\text { médias e os pobres são sub-representados } \\
\text { - Lentidão na execução dos programas, frustrando os participantes } \\
\text { - Clivagens entre o PT e o executivo } \\
\text { - Risco de reificação do movimento popular, tornando difícil a separação clara } \\
\text { entre seu papel e o do governo } \\
\text { - Decisões fragmentadas e demandas de curto prazo podem prejudicar o plane- } \\
\text { jamento urbano e projetos de longo prazo } \\
\text { - Supremacia dos movimentos sociais e do executivo sobre o legislativo na ques- } \\
\text { tão da alocação de recursos }\end{array}$ \\
\hline
\end{tabular}


tratégias de reação não diretamente contra o OP, mas contra o executivo municipal. ${ }^{13}$

Essas constatações levantam dúvidas sobre o futuro do OP caso as coalizões partidárias que o implementaram não sejam reeleitas. Por outro lado, se o OP funciona da forma como a literatura o descreve e analisa, então pode-se esperar que um de seus resultados seja fortalecer os movimentos sociais e a aceitação do programa pela sociedade, convencendo coalizões diversas a mantê-lo nas cidades onde a experiência é considerada bem-sucedida.

Embora arriscando excessiva simplificação das questões debatidas nesta seção, o Quadro 1 apresenta um sumário dos principais resultados do OP em Porto Alegre e em Belo Horizonte.

\section{DEBATENDO ARGUMENTOS E TESES}

A literatura produzida pela ciência política e pela administração pública ainda não apresenta respostas claras e precisas sobre por que algumas experiências políticoinstitucionais são adotadas e quais as razões para seu sucesso ou fracasso. A falta de moldura analítica teoricamente coerente, capaz de guiar avaliações das práticas político-administrativas, induz a critérios e conclusões extremamente divergentes sobre os resultados das políticas públicas, em especial as de formato participativo. Além do mais, em países caracterizados por enormes desequilíbrios sociais, econômicos e regionais, deve-se ter cuidado ao desenhar conclusões gerais com base nos resultados de um pequeno número de programas participativos. Avaliações e generalizações sobre as experiências brasileiras com o OP, por exemplo, podem muito facilmente resvalar na armadilha de se acreditar que o OP é possível somente no "moderno" e "desenvolvido" Sul e Sudeste do país, e impossível no Nordeste, rotulado, em geral, de "atrasado" e "clientelista". Ademais, na análise dos principais resultados do OP, é importante relembrar a advertência de Santos (1993): a busca de lógica única no terreno da ação coletiva é inútil, em razão da multiplicidade de fatores que se articulam para chegar a determinado resultado de política pública. O reconhecimento dessas limitações deve orientar o pesquisador na tarefa de debater e avaliar as teses e os argumentos sobre o OP.

Assim, a falta da moldura analítica mencionada abre espaço para que o OP seja avaliado de acordo com a ideologia, os interesses ou as agendas específicas dos avaliadores e/ou de suas instituições. Fora da literatura aqui analisada, muitas das visões sobre o OP não escondem esse escasso rigor analítico. Alguns críticos do OP o vêem como uma oportunidade de os partidos de esquerda de exercerem o mesmo "velho clientelismo" das administrações conservadoras, embora sem a intermediação dos vereadores. Há críticos que afirmam que o OP é um tipo de altruísmo ingênuo. Outros ainda argumentam, cinicamente, que o OP faz com que os pobres decidam para que eles culpem a si mesmos, e não ao governo, quando não conseguirem recursos suficientes para suas demandas. A dificuldade dessas visões, além de essencialmente normativas, é que nenhuma delas fornece critérios pelos quais a experiência possa ser avaliada. $\mathrm{O}$ mesmo acontece com aqueles que advogam a existência do OP apenas porque apóiam os governos e/ou os partidos com ele comprometidos.

O OP é uma experiência induzida e coordenada pelo governo e tem sido considerada um sucesso nas cidades aqui analisadas. Essa aprovação é provavelmente a razão da reeleição das coalizões partidárias que o estão implementando. As constantes mudanças nas regras, procedimentos e no funcionamento do OP mostram que a experiência faz parte de um aprendizado para os envolvidos. Os casos aqui revisitados também demonstram que os problemas do OP não fizeram seus defensores desistir da experiência. Isso indica que talvez o OP esteja enfrentando uma das práticas mais comuns das políticas públicas brasileiras: seu caráter errático e inconstante. ${ }^{14}$ Apesar de mudanças nas facções político-partidárias em Porto Alegre e em Belo Horizonte ao longo da experiência do OP, o programa vem sendo mantido e fortalecido. A aceitação popular, que vem se manifestando através do apoio dos movimentos sociais e do resultado das pesquisas de opinião, também deve estar contribuindo para a sobrevivência do OP.

As seções anteriores mostraram que algumas teses/argumentos relacionadas com os objetivos e os resultados do OP se confirmam, dado que ocorrem em ambos os casos estudados. Outras teses/argumentos, todavia, merecem maior atenção e debate, e são objeto das subseções seguintes.

\section{"Empoderamento" dos Pobres}

Os números e as análises mostram que, com o OP, grupos de baixa renda, mas não os muito pobres, passaram a ter influência sobre o processo decisório de alocação de uma porcentagem dos recursos públicos locais. Apesar da porcentagem ser relativamente pequena - no caso de Porto Alegre, por exemplo, a média foi de $13,1 \%$ entre 1990 e 1996 - o OP é uma política importante no sentido de 
prover alguma infra-estrutura em comunidades carentes. A questão da limitação dos recursos financeiros é, no entanto, mais crucial do que aparenta à primeira vista. Isso porque, apesar de alguns governos municipais estarem comprometidos com a reversão de prioridades e com transformar investimentos nas áreas mais pobres da cidade de favores em direitos, esses governos podem realizar apenas uma fração muito reduzida das necessidades das comunidades de baixa renda. Nesse sentido, o mérito do OP parece não estar necessariamente nos ganhos materiais para segmentos de baixa renda, mas sim na ampliação da participação e do poder de decisão para grupos anteriormente excluídos do processo decisório.

Além das limitações financeiras, outra questão importante em relação à alocação de recursos permanece. O que as experiências aqui analisadas sugerem é que em sociedades altamente desiguais como a brasileira, segmentos de baixa renda estão despendendo considerável energia e tempo no debate sobre a alocação de recursos públicos. Como sugeri anteriormente, isto é, de fato, "empoderamento" ou autogoverno sobre determinadas políticas públicas. Mas é preciso lembrar que as classes média e rica têm acesso, sem nenhum dispêndio de energia ou tempo, à infra-estrutura pela qual os segmentos de baixa renda lutam.

A tese de "empoderamento" dos pobres pode ser também questionada pela renda dos participantes. Apesar de o OP não estar atingindo os muito pobres, a experiência está alcançando outro importante objetivo: redirecionando recursos para áreas que historicamente sempre estiveram excluídas das ações governamentais. Evidências mostram que, até então, a única forma de essas áreas receberem investimentos era pela vinculação das respectivas comunidades a vereadores e candidatos a prefeitos durante os períodos eleitorais. Esses investimentos passavam a gerar dependência e eram, em geral, associados a favores e não a direitos. Essas áreas, que compõem grande parte das cidades brasileiras, são deixadas ao próprio destino ou controladas por gangues de todo tipo, como vem mostrando a mídia, principalmente na periferia do Rio de Janeiro e de São Paulo. Ao estimular a auto-organização dessas comunidades, o OP abre a oportunidade para que os moradores de baixa renda vejam a si mesmos como cidadãos, não mais condenados a sobreviver à margem do Estado ou sob a proteção de uma gangue. Assim, a tese do "empoderamento" dos pobres poderia ser substituída por aquela que vê o OP como uma forma de compensar áreas de baixa renda pela negligência histórica de administra- ções locais anteriores e pela possibilidade que abre para que o governo se faça presente em áreas até então fora de sua intervenção.

\section{Redução do Clientelismo}

A literatura analisada defende que uma das razões do sucesso do OP está no cumprimento dos valores constitutivos da participação: credibilidade, confiança, transparência, accountability, "empoderamento" de cidadãos comuns, solidariedade, etc. A maior parte da literatura acrescenta a essa lista a redução do clientelismo e do patrimonialismo. Discutir esses dois fenômenos e suas razões está fora dos objetivos deste trabalho. É importante, no entanto, mencionar que no caso do clientelismo a literatura também parece reconhecer que a prática continua viva em algumas cidades que adotaram o OP. Separar uma parte dos recursos do orçamento para que os vereadores façam sua distribuição foi a fórmula encontrada em Belo Horizonte para reduzir a resistência dos vereadores ao OP. Por outro lado, esforços para melhorar as regras do OP na medida em que a experiência foi amadurecendo podem indicar a possibilidade de, no longo prazo, poderse isolar o OP do clientelismo. Conclui-se que, apesar de Porto Alegre ter sido a primeira cidade em que o OP se transformou em uma política pública contínua, outras cidades, como Belo Horizonte, o estão adaptando às suas circunstâncias locais, o que pode ser interpretado como um sinal de amadurecimento e pragmatismo. Por outro lado, argumenta-se também que a tese de que o OP é uma forma de mudar "velhas práticas clientelistas" pode não se sustentar em todas as cidades que o implantaram.

\section{“Empoderamento" dos Desorganizados}

A tese de que o OP abriu o poder para os desorganizados também exige debate e análise mais aprofundados. Como foi mencionado a partir dos dados de Nylen (2000b), um número significativo de participantes do OP eram engajados em ações comunitárias antes do OP. Dessa forma, não se pode afirmar que o OP motivou os desorganizados a participar do processo decisório e da política pela primeira vez. A tese poderia ser refeita para interpretar o OP como um mecanismo capaz de assegurar um ativismo político não elitista, na expressão de Nylen. Mudar o foco da tese não implica reduzir a importância das conquistas políticas do OP, especialmente em um país onde a assimetria de poder é imensa. 


\section{Vontade Política}

A tese de que o OP é o resultado de forte vontade política característica de partidos de esquerda também requer debate. Explicações baseadas em visões voluntaristas são, em geral, problemáticas. Primeiro, essas visões pressupõem que é possível mudar a realidade pela ação de poucos grupos, em especial grupos não hegemônicos no cenário decisório local ou nacional. Segundo, essas visões desconsideram a rede de circunstâncias e tradições que existem em qualquer tipo de ação política. Terceiro, elas não explicam por que alguns governos do PT deram prioridade a outras políticas para integrar grupos excluídos, como a bolsa-escola em Brasília. Não explicam também por que o OP não foi bem-sucedido em Brasília, São Paulo e Santos, apesar das tentativas de seus governantes. A tese da vontade política poderia então ser refeita para argüir que alguns governos locais escolheram o OP como sua marca registrada porque o programa lhes dá a oportunidade de aumentar a coalizão de governo. A recompensa dessa opção tem sido as sucessivas vitórias eleitorais que os governos locais que privilegiaram o OP têm conseguido.

\section{Aumento das Receitas Locais}

Outra tese que merece discussão é a que associa o sucesso do OP à reforma fiscal implantada por administrações petistas. Isso porque não foi apenas o PT que assumiu o compromisso de aumentar os recursos próprios e de ajustar as finanças locais. Essas políticas foram adotadas por várias cidades brasileiras, independentemente de filiação partidária.

Outro problema com essa tese relaciona-se com o padrão de investimento e gasto público nas cidades brasileiras. Apesar de o Brasil ser uma república federativa, a competência para legislar sobre inúmeras matérias é exclusivamente federal. Os governos subnacionais têm pouco espaço para adotar legislação e política próprias em várias matérias, especialmente se comparado com outros países federativos. Apesar dessa uniformidade, no entanto, o padrão de investimento das cidades brasileiras varia consideravelmente, especialmente no gasto social. Esse ponto é importante porque, apesar de a Constituição estabelecer que os municípios são os principais provedores da educação fundamental, outros níveis de governo também podem provê-la. Por essa razão, muitos estados eram, até a criação do Fundef, os principais provedores da educação fundamental. Como a despesa com educação é alta, ocupando, em geral, entre o primeiro e o terceiro lugares no total da despesa dos estados e municípios, se um município não era o principal responsável pela sua provisão, haveria mais recursos disponíveis para investir em políticas como o OP.

Dados das contas públicas subnacionais entre $1986 \mathrm{e}$ 1990, por exemplo, mostram que, no caso de Porto Alegre, a administração municipal despendia em educação valores inferiores à média das demais capitais da região. Somente após 1991 a despesa de Porto Alegre atingiu a mesma média das demais capitais da Região Sul. No mesmo período, a despesa de Belo Horizonte com o Ensino Fundamental era semelhante à de Porto Alegre.

No que se refere ao número de matrículas no Ensino Fundamental, os governos locais no Brasil eram responsáveis, nos anos 80 , por cerca de $30 \%$ delas. As diferenças entre as regiões era considerável: as matrículas sob responsabilidade dos governos locais no Nordeste e no Norte eram mais altas do que a média nacional $(45 \% \mathrm{e}$ $39 \%$, respectivamente), enquanto no Sul e no Sudeste as taxas eram de $18 \%$ e $30 \%$, respectivamente (Souza, 1997). Esses números podem indicar que uma das razões para um bem-sucedido OP seria, paradoxalmente, um papel reduzido do governo local na provisão do Ensino Fundamental, o que deixava mais recursos orçamentários livres para investimento em infra-estrutura, principal item da despesa do OP em Porto Alegre e em Belo Horizonte.

No entanto, após 1998, com a instituição, por iniciativa do governo federal, do Fundef, criou-se um sistema que pune financeiramente os municípios que não aumentarem as matrículas no Ensino Fundamental. Dessa forma, e considerando que os recursos alocados em educação aumentaram no final dos anos 90, talvez seja possível argumentar que o OP possa ter atingido o limite máximo de recursos disponíveis, não apenas por causa da política de controle fiscal, mas também pelo papel ampliado que os municípios passaram a ter na educação fundamental. A mudança promove mais impacto nos municípios mais populosos, especialmente naqueles que tradicionalmente investiam menos em educação fundamental em virtude da presença mais ativa do estado, como era o caso de Porto Alegre e de Belo Horizonte.

\section{Aumento da Representação Política}

Uma última questão merece ser debatida: a relação entre o OP e o Legislativo local. Essa questão está no centro do debate corrente sobre o funcionamento do sistema re- 
presentativo em países democráticos, heterogêneos e que perseguem políticas participativas. Com políticas como o $\mathrm{OP}$, os vereadores são instados a partilhar sua prerrogativa de decidir sobre o que muitos vêm como seu principal papel, isto é, a alocação de recursos públicos, não só com o executivo mas também com os movimentos sociais organizados em torno do OP. Além do mais, com o OP; os vereadores e a elite local que eles representam perdem o monopólio da representação dos interesses locais e seu papel de um dos principais atores na sensível e conflituosa decisão sobre alocação de recursos públicos escassos. Ademais, e como foi analisado por Dias (2000), a instituição de uma política como o OP gera problemas teóricos e práticos que afetam o funcionamento do sistema formal de representação de interesses, base das democracias ocidentais.

A questão da representação não afeta apenas os vereadores. A literatura analisada faz referências, embora esporádicas, a problemas de accountability e transparência entre os delegados do OP e aqueles que eles representam. Apesar de eventualmente mencionar essa questão, a literatura não lhe dedica maior reflexão. Permanece obscuro se os mecanismos de participação têm reproduzido os mesmos problemas encontrados nos sistemas formais de representação.

\section{CONSIDERAÇÕES FINAIS}

Este artigo sintetizou e debateu as principais possibilidades e limites do orçamento participativo em duas cidades brasileiras, buscando correlacionar a experiência do OP com a construção de instituições democráticas e da cidadania e com a perspectiva do autogoverno local. Sejam quais forem os méritos e os problemas dessa experiência, é importante realçar que não existe um modelo de OP, mas sim várias experiências que adquiriram contornos diversificados. O maior risco do OP talvez esteja na busca de copiálo, tendo em vista sua alta aceitação e visibilidade em cidades que fizeram dele sua marca registrada. A força do OP em Porto Alegre e em Belo Horizonte parece estar na sua capacidade de inserir pessoas e comunidades historicamente marginalizadas no processo político-decisório formal. Ao fazer com que esses cidadãos passem a ter o direito de decidir - e não apenas de ser ouvidos - é possível que se esteja gerando um impacto de mais longo prazo na extremamente assimétrica correlação de forças no Brasil. Mas pode-se estar também abalando o frágil equilíbrio entre o executivo e o legislativo locais, com conseqüências para o sistema representativo formal.

\section{NOTAS}

E-mail da autora: celsouza@usp.br

Este artigo é uma síntese de um trabalho que integra a pesquisa "Governança Urbana, Pobreza e Parceria", coordenada pelo International Development Department da School of Public Policy da Universidade de Birmingham (GB). Agradeço a Marta Arretche, Richard Batley, Nick Devas, Marcus Melo, David Satterthwaite e Mark Setzler pelos inúmeros comentários e sugestões.

1. A literatura sobre desenvolvimento, comunitarismo e capital social vem buscando enfrentar essa questão. Para tentar desvendar a combinação dessas condições em duas cidades brasileiras, a partir do conceito de governança, ver Boschi (1999a).

2. A experiência de Piracicaba, embora não tenha sido única, era rara porque os prefeitos eleitos pelo MDB tendiam a deixar o partido e filiarse à Arena logo após a eleição, como forma de receber recursos federais e estaduais em uma época em que os recursos públicos estavam fortemente concentrados na esfera federal. Castro (1988) registra, por exemplo, que nas eleições locais de 1976, dos 101 prefeitos eleitos pelo MDB 78 se transferiram para a Arena logo após as eleições.

3. Outros governos locais analisados pelo Instituto Pólis foram Santos (Ferreira et alii, 1994), Ronda Alta e São João do Triunfo (Ferreira e Ricci, 1992). Programas setoriais de cultura, urbanização de favelas e crianças em situação de risco também foram analisados pela mesma instituição. Mais recentemente, outras ONGs, como o Ibase, passaram a desempenhar papel importante na disseminação e no treinamento de políticas participativas.

4. Abers (1998), por exemplo, registra que, com a introdução dos novos índices, o IPTU em Porto Alegre teve um aumento de $142 \%$. Santos (1998) menciona que em 1990 o IPTU de Porto Alegre representava $5,8 \%$ dos recursos municipais; em 1992, 13,8\% e, mais recentemente, varia entre $17 \%$ e $18 \%$. Esses números, é claro, impressionam, mas outras capitais, como Belo Horizonte e Vitória, registraram incrementos ainda mais expressivos.

5. A experiência do Recife foi recentemente analisada por Melo et alii (2000).

6. Sobre os dilemas da participação na esfera local, ver Jacobi (1990).

7. A defesa do autogoverno local e da participação comunitária não é, obviamente, uma bandeira apenas dos partidos ou movimentos de esquerda. Alguns teóricos da escolha pública, por exemplo, defendem a substituição da democracia representativa pela democracia direta no território local como forma de enfrentar problemas como o rent-seeking e a maximização do orçamento. Ver, por exemplo, Santerre (1986).

8. Essa literatura encontra-se disseminada em centenas de teses, dissertações, artigos e trabalhos apresentados em seminários. A seleção feita neste trabalho privilegiou teses de doutorado, artigos em periódicos especializados e trabalhos de ONGs que focalizam o tema da participação.

9. Vários trabalhos mostram que a maioria das cidades brasileiras, especialmente onde vivem os mais pobres, têm poucos recursos disponíveis e pouco espaço para aumentar a arrecadação de recursos próprios, dada a falta de atividade econômica e o tamanho da população pobre. 10. O exemplo mais conhecido ocorreu em Brasília, com o programa bolsa-escola instituído pelo então governador Cristovam Buarque, do PT, e abolido pelo seu sucessor, Joaquim Roriz.

11. Os cálculos de Setzler (2000) mostram que 38,4\% das pessoas em Porto Alegre e $27,7 \%$ em Belo Horizonte participam de algum tipo de associação. Como indicador de confiança comunitária, 40,7\% em Porto Alegre e $37,3 \%$ em Belo Horizonte acreditam que as associações defendem seus interesses. A desconfiança dos moradores de ambas as cidades, no entanto, é maior do que a confiança: $45,7 \%$ em Porto Alegre e 53,3\% em Belo Horizonte não acreditam que as associações ou os políticos defendam seus interesses.

12. Práticas clientelistas ainda vigentes na Câmara de Vereadores de Belo Horizonte em relação ao orçamento foram relatadas por Azevedo e Avritzer (1994), Pereira (1996) e Setzler (2000). 
13. Até onde tenho conhecimento, o trabalho de Dias (2000) é pioneiro na análise sobre os efeitos da participação direta da população na distribuição orçamentária em relação à Câmara de Vereadores. Além do pioneirismo, o trabalho introduz importante discussão teórica e empírica sobre os dilemas entre representação e participação.

14. Essa tem sido uma característica recorrente no Brasil, inclusive durante o regime militar, como mostrado por Batley (1991). No entanto, a literatura recente sobre melhores práticas vem argumentando que programas reconhecidos como bem-sucedidos estão sendo mantidos pelos governos seguintes, independentemente de diferenças ideológico-partidárias.

\section{REFERÊNCIAS BIBLIOGRÁFICAS}

ABERS, R. "From clientelism to co-operation: local government, participatory policy, and civic organizing in Porto Alegre, Brazil". Politics \& Society, v.26, n.4, 1998, p.511-23.

"Overcoming the dilemmas of participatory democracy: the participatory budget policy in Porto Alegre, Brazil". Trabalho apresentado no Encontro Anual da LASA. Miami, 2000.

ARRETCHE, M. Estado federativo e políticas sociais: determinantes da descentralização. Rio de Janeiro, Revan; São Paulo, Fapesp, 2000.

AZEVEDO, S. "Políticas públicas e governança em Belo Horizonte". Cadernos Ippur XI, v.1, n.2, 1997, p.63-74.

AZEVEDO, S. e AVRITZER, L. "A política do 'orçamento participativo': formas de relacionamento entre Estado e sociedade". Trabalho apresentado no Encontro Nacional da ANPOCS. Caxambu, 1994.

BATLEY, R. "Urban management in Brazil". Birmingham, Development Administration Group, Institute of Local Government Studies, University of Birmingham, mimeo, 1991.

BOSCHI, R. "Descentralização, clientelismo e capital social na governança urbana: comparando Belo Horizonte e Salvador". Dados - Revista Brasileira de Ciências Sociais, v.42, n.4, 1999a, p.528-53.

"Governança, participação e eficiência das políticas públicas: exame de experiências municipais no Brasil”. In: MELO, M.A. (org.). Reforma do Estado e mudança institucional no Brasil. Recife, Fundação Joaquim Nabuco, Ed. Massangana, 1999b, p.255-84.

CASTRO, M.H.G. "Equipamentos sociais e política local no pós-64: dois estudos de caso". Espaço \& Debates, v.24, 1988, p.67-74.

COSTA, S. "Movimentos sociais, democratização e a construção de esferas públicas locais". Dados - Revista Brasileira de Ciências Sociais, v.12, n.35, 1997, p.112-24.

DESPOSATO, S.W. "Institutional theories, and social realities, and parties: a comparison of legislative politics in 5 Brazilian states". Trabalho apresentado no Encontro Anual da LASA. Miami, 2000.

DIAS, M.R. Na encruzilhada da teoria democrática: efeitos do orçamento participativo sobre a Câmara Municipal de Porto Alegre. Tese de Doutoramento. Rio de Janeiro, Iuperj, 2000.

FEDOZZI, L. Orçamento participativo: reflexões sobre a experiência de Porto Alegre. Porto Alegre, Tomo Editorial; Rio de Janeiro, Ippur/Fase, 1997.

FERREIRA, A.L.S.S. Lages: um jeito de governar. São Paulo, Instituto Pólis, 1991.

FERREIRA, A.L.S.S. et alii. Santos: o desafio de ser governo. São Paulo, Instituto Pólis, 1994.

FERREIRA, A.L.S.S. e RICCI, R. Estudos de gestão: Ronda Alta e São João do Triunfo. São Paulo, Instituto Pólis, 1992.

HIRSCHMAN, A.O. Exit, voice and loyalty. Cambridge, Mass., Harvard University Press, 1970.

JACOBI, P. "Descentralização municipal e participação dos cidadãos: apontamentos para o debate". Lua Nova 20, 1990, p.121-143.
JACOBI, P. e TEIXEIRA, M.A.C. "Orçamento participativo: co-responsabilidade na gestão das cidades". São Paulo em Perspectiva. São Paulo, Fundação Seade, v.10, n.13, 1996, p.119-128.

JAYME, Jr. F. e MARQUETTI, A. "Descentralização tributária e performance econômica das capitais brasileiras: 1989-1994". Trabalho apresentado no Encontro Anual da LASA, Chicago, 1998.

LARANGEIRA, S. "Gestão pública e participação: a experiência do orçamento participativo em Porto Alegre". São Paulo em Perspectiva. São Paulo, Fundação Seade, v.10, n.13, 1996, p.129-37.

MATTHAEUS, H. Urban management, participation and the poor in Porto Alegre/Brazil. Tese de Doutorado. Birmingham, Institute of International Development, School of Public Policy, 1995.

MELO, M.A. "Crise federativa, guerra fiscal e "hobbesianismo municipal': efeitos perversos da descentralização?". São Paulo em Perspectiva. São Paulo, Fundação Seade, v.10, n.13, 1996, p.11-20.

MELO, M.; REZENDE, F. e LUBAMBO, C. "Urban governance, accountability and poverty: the politics of participatory budgeting in Recife, Brazil”. Recife, mimeo, 2000.

NAVARRO, Z. "Affirmative democracy and redistributive development: the case of participatory budgeting in Porto Alegre, Brazil [19891997]”. Porto Alegre, mimeo, 1997.

NYLEN, W. "The making of loyal opposition: the Worker's Party (PT) and the consolidation of democracy in Brazil". In: KINGSTONE, P. e POWER, T.J. (eds.). Democratic Brazil: actors, institutions, and processes. Pittsburgh, University of Pittsburgh Press, 2000a, p.126-43.

"Testing the empowerment thesis: the participatory budget in Belo Horizonte \& Betim, Brazil". Trabalho apresentado no Encontro Anual da LASA. Miami, 2000b.

PEREIRA, M. de L.D. Negociação e parcerias: a gestão urbana democrático-participativa. Tese de Doutorado. São Paulo, Departamento de Ciência Política da USP, 1999.

PEREIRA, M. de L.D. et alii. "Experiências de orçamento participativo na democratização da gestão urbana: a dimensão político-eleitoral". Trabalho apresentado no Encontro Anual da ANPOCS, Caxambu, 1996.

PINTO, V.P. Prefeitura de Fortaleza: administração popular - 1986/88. São Paulo, Instituto Pólis, 1992.

SANTERRE, R.E. "Representative versus direct democracy: a Tiebout test of relative importance". Public Choice, v.48, 1986, p.55-63.

SANTOS, B. de S. "Participatory budgeting in Porto Alegre: toward a redistributive democracy". Politics \& Society, v.26, n.4, 1998, p.461-510.

SANTOS, W.G. Razões da desordem. Rio de Janeiro, Rocco, 1993.

SETZLER, M. "Democratizing urban Brazil: institutional legacies and determinants of accountability in local elections and legislatures". Trabalho apresentado no Encontro Anual da LASA. Miami, 2000.

SOMARRIBA, M. e DULCI, O. "A democratização do poder local e seus dilemas: a dinâmica atual da participação popular em Belo Horizonte". In: DINIZ, E. e AZEVEDO, S. (orgs.). Reforma do Estado e democracia no Brasil. Brasília, Editora UnB, 1997, p.391-425.

SOUZA, C. Constitutional engineering in Brazil: the politics of federalism and decentralization. Londres, Macmillan; Nova York, St. Martin's Press, 1997.

TENDLER, J. Good government in the tropics. Baltimore, The Johns Hopkins University Press, 1997.

VILLAS BOAS, R. "Os canais institucionais de participação popular". In: VILLAS BOAS, R. (org.). Participação popular nos governos locais. São Paulo, Instituto Pólis, 1994.

WAMPLER, B. "Participatory publics and the executive: participatory budgeting programs in Recife and Porto Alegre". Trabalho apresentado no Encontro Anual da LASA. Miami, 2000.

WORLD BANK. Governance: The World Bank's experience. World Bank, Washington, D.C., 1994. 